\title{
FLUXO DE ENERGIA E DE MASSA NA ANÁLISE DE EFICIÊNCIA DA LINHA DE PRODUÇÃO DE UMA SERRARIA DE PEQUENO PORTE
}

\section{FLOW OF ENERGY AND MASS IN THE ANALYSIS OF EFFICIENCY OF THE PRODUCTION LINE OF ONE SMALL SAWMILL FACTORING}

\author{
Ailton Teixera do Vale ${ }^{1}$ Alexander Rudolph Marin Sablowski ${ }^{2}$ \\ RESUMO
}

Neste trabalho, é feita a análise da eficiência de produção de uma serraria de pequeno porte, localizada no estado de São Paulo, utilizando como ferramentas a "análise de fluxo de massa" e "análise de fluxo de energia". O objetivo foi avaliar a linha de produção e comparar as ferramentas utilizadas em função dos resultados obtidos e aplicabilidade. Concluiu-se que o "lay out" de disposição dos maquinários deve ser alterado e deve-se utilizar um melhor planejamento do gabarito de corte para que o sistema se torne viável em função da baixa eficiência com grande porcentagem de perda e uso inadequado dos equipamentos e matéria-prima. As ferramentas forneceram resultados similares e por causa da aplicabilidade, propõe-se a utilização da "análise de fluxo de massa" para avaliação de comportamento produtivo de serrarias.

Palavras-chave: fluxo de massa; fluxo de energia; eficiência; produção.

\section{ABSTRACT}

This is the analysis of the efficiency of production of one small sawmill, located in São Paulo, using as an instrument of study the "Mass and Energy Flow", available in the production line. It was concluded that the disposal of the machines should be modified, and that the inclusion of a process of planning of cut design is necessary so that the system becomes viable, since the current configuration presents low income with great percentage of loss and inadequate use of equipment and raw material. Concerning the tools, similar results were found and because of its ease of utilization the "mass and flow" is recommended to the sawmill pattern evaluation.

Keyword: mass flow; energy flow; efficiency; production.

\section{INTRODUÇÃO}

A otimização de uma linha de produção e conseqüente aumento de sua sustentabilidade ambiental, deve observar primeiro a eficiência e não a sua capacidade de produção. $\mathrm{O}$ aumento da eficiência dá-se pela da redução de quantidade de matéria-prima para geração de uma mesma quantidade de produto.

A sustentabilidade ambiental se integra progressivamente de forma ativa nas questões econômicas e de produção, desde que a indústria compreendeu a necessidade de racionalização do uso dos recursos naturais. Sendo essa racionalização fruto não apenas da pressão social sobre as questões ambientais, mas da necessidade da indústria em garantir a sua própria manutenção por meio de um estoque regular de energia e matéria-prima.

Assim as ferramentas de análise do comportamento produtivo devem observar a equalização entre a quantidade de matéria que entra na linha de produção e a quantidade de produto gerada. Sendo o ponto referencial para a entrada de matéria-prima, a quantidade de produto que viabiliza o empreendimento.

A "análise de fluxos mássicos" é a base para ferramentas de avaliação de comportamento de produção e ambiental encontradas no conceito de "Ecologia Industrial". Neste trabalho, aplica-se a análise de fluxo de massa e a análise de fluxo de energia que são ferramentas normalmente utilizadas em estudos de comportamento ambiental associado a comportamento produtivo de sistemas macro. Mas estudos recentes como este têm buscado a sua utilização em sistemas micro, como linhas de produção de uma unidade industrial. Essas ferramentas permitem a análise direta do fluxo da matéria e energia envolvida no sistema de produção, identificando e quantificando os pontos de ineficiência que, ao serem melhorados, possibilitam uma maior produção por unidade de matéria-prima. Ou seja, a identificação e correção desses pontos

1. Engenheiro Florestal, Dr., Professor Adjunto do Departamento de Engenharia Florestal, Universidade de Brasília, Campus Universitário, CEP 70910-900, Brasília (DF). ailtontv@unb.br

2. Engenheiro Florestal, Doutorando pelo Curso de Pós-Graduação em Engenharia Florestal, Universidade de Brasília, Campus Universitário, CEP 70910-900, Brasília (DF).wskibr@yahoo.com.br

Recebido para publicação em 26/05/2003 e aceito em 14/07/2006. 
individualmente ou em conjunto acarretam a redução do desperdício de energia e massa e, conseqüente, melhor equalização entre a entrada e a saída do sistema pré-definido.

Essas ferramentas fornecem respostas que variam de acordo com o tipo de industria avaliada e respectiva matéria-prima. Sendo importante o estudo da resposta fornecida pelas diferentes ferramentas para cada tipo de indústria e definição daquela que permite a melhor relação custo/benefício.

Com esse intuito, neste trabalho, utilizou-se a "análise de fluxo de massa" e "análise de fluxo de energia" para avaliação da eficiência de produção de uma serraria de pequeno porte.

\section{REVISÃO DE LITERATURA}

Segundo Ferrão (1998), a busca da sustentabilidade é função não somente da manutenção da qualidade de vida no planeta, mas também a necessidade de se perpetuar o estoque de matéria-prima para o sistema industrial que sempre tem início na utilização de recursos naturais.

Em "Beyond the Limits", o grupo MIT (Massachustess Institute of Technology), citado por (Ferrão, 1998), conclui que:

$\mathrm{Na}$ ausência de reduções significativas nos fluxos de matéria e energia, nas próximas décadas, verificar-se-á um declínio acentuado no consumo per capita de alimentos, energia e produção industrial;

Esse declínio não é no entanto inevitável. Sendo necessárias duas mudanças. A primeira consiste numa revisão das políticas e práticas que perpetuam o crescimento material e demográfico, a segunda consiste num aumento rápido na eficiência com que os materiais e a energia são utilizados;

Uma sociedade sustentável é ainda técnica e economicamente possível e é preferível a uma sociedade que procura resolver os seus problemas por uma lógica de constante expansão;

Uma das ferramentas para análise e racionalização da produção, seja qual for o produto desenvolvido, é a "Análise de Fluxo de Massa" que possibilita visualizar o percurso de uma determinada substância dentro de um sistema definido e avaliar a eficácia com que está sendo utilizada pela identificação de pontos que influenciam significativamente a sua eficiência ambiental e produtiva.

Ao analisar o metabolismo de um sistema em termos de energia ou matéria, ou o fluxo mássico entre esse sistema e seu ambiente, pode-se fazer uma revisão geral em termos de matéria ou energia (ou ambos), ou selecionar determinados fluxos de materiais ou substâncias químicas de um produto. Normalmente essas análises se fazem pela comparação entre as taxas de produção e as taxas de consumo de determinados recursos dentro do sistema de referência. Como exemplo, cita-se a análise de saída de um sistema (emissões e desperdícios) relacionada à capacidade de absorção ou armazenamento dentro do ecossistema, (Hüttler e Kowalski ,1998).

Segundo Behrensmeyer et al. (1998), o termo inglês "material" pode ser diferenciado pelos termos "substância" e "produto". O produto se refere ao resultado de um processo de produção que seja usado comercialmente, mas, em muitos casos, implica também em uma composição heterogênea.

Por isso, tem-se usado a diferenciação entre os métodos de análise que focalizam os fluxos de uma substância dos fluxos de produto, buscando aumentar o valor da informação e minimizar o risco do engano.

O fluxo é o cálculo e a apresentação sistemática dos resultados. Dessa forma, o fluxo dos materiais é o movimento da matéria ou da energia de um processo ou posição a um outro processo ou posição durante um determinado período de tempo.

E os "Limites do sistema" são as fronteiras de início e fim, ao qual o fluxo a ser estudado está confinado. Esses limites são função do objetivo do estudo.

\section{MATERIAL E MÉTODO}

A análise foi elaborada tomando-se como sistema a linha de produção da serraria de pequeno porte que processa, em média, $200 \mathrm{~m}^{3}$ de toras de Eucalyptus sp por dia. Os limites do sistema são a entrada de toras na linha de beneficiamento (entrada de material), e a madeira beneficiada destinada ao estoque ou entrega em conjunto com os resíduos gerados (saída de material). O tempo de levantamento de dados foi 11 dias (8 horas/dia), sendo ele executado por máquina, permitindo avaliar o sistema em todos os seus pontos e 
o fluxo total foi obtido pelo somatório deles. Para cálculo da eficiência em massa e rendimento energético, todos os dados foram transformados em consumo por hora efetiva de trabalho (he) que permite visualizar o equilíbrio existente ao longo da linha. Mas também são apresentadas as análises por turno de trabalho (8 horas), para comparação entre os resultados.

Os valores de eficiência sempre serão superiores ao de rendimento por desconsiderar a produção de serragem. E a diferença de valores, enquanto o sistema estiver equilibrado, será próximo do fator de produção mínima de serragem adotado que, neste trabalho, é de $4 \%$.

Para o balanço de massa, todos os volumes foram convertidos em massa $(\mathrm{kg})$, por meio de cálculo direto com a massa específica da madeira utilizada que é o eucalipto.

Para o balanço de energia, converteu-se a energia elétrica $(\mathrm{kWt})$ em energia calorífica (kcal) que foi somada a energia corpórea consumida pelos operários e ao poder calorífico dos resíduos. Este total foi subtraída da energia (kcal) do poder calorífico da massa de madeira (kcal).

\section{Levantamento de dados para o fluxograma}

Inicialmente foi elaborado o fluxograma da linha de produção, visualizando os maquinários, equipamentos, que representam os pontos de entrada e saída de energia e material madeira bem como os funcionários envolvidos.

\section{Levantamento de dados para balanço de massa e energia}

Alguns dados foram obtidos por medição direta, e outros pela consulta à bibliografia existente ou estimada em função dos dados medidos.

\section{Dados bibliográficos}

Um operário consome 525kcal/ he de trabalho (Cheicel (1973) citado por Serra et al, 1979);

Um kwh equivale a $860 \mathrm{kcal}$ de energia (BEN, 2002);

Produção de costaneiras no desdobro de toras eucalipto: $14 \%$ do volume total da matéria-prima de entrada (Garcia citado por Borges, 1993);

Produção de serragem após processamento: $4 \%$ do volume total da matéria-prima de entrada (Garcia citado por Borges, 1993);

\section{Dados medidos}

Volume de toras $\left(\mathrm{m}^{3}\right)$ na entrada: obtido pela medição do diâmetro $(\mathrm{m})$ na base e topo, e o comprimento $(\mathrm{m})$ de cada tora e posterior somatório de todos volumes $\left(\mathrm{m}^{3}\right)$ encontrados, fornecendo o total ao longo do período de levantamento que, dividido pelo número total de dias, forneceu a média diária.

Volume $\left(\mathrm{m}^{3}\right)$ de peças processadas por máquina: $\mathrm{Na}$ serra circular 1 e 2 , e nas destopadeiras, efetuou-se a medição das arestas das peças produzidas e cálculo de seu volume. Pelo somatório dos volumes calculados, estabeleceu-se o total de madeira processada. Sendo que o volume processado na primeira máquina da linha representa o volume de entrada na máquina subseqüente.

Horas efetivas (he) de trabalho dos operários: foi obtido por cronometragem direta. (kwh).

Quantidade de energia consumida por máquina: foi executada por medição direta com potenciômetro

Teor de umidade da madeira de eucalipto: obtido pela amostragem ao longo de 10 toras, no sentido longitudinal e radial. Sendo a metodologia de análise baseada no método gravimétrico de Vital (1997), sendo o valor apresentado a média do total da amostragem.

Massa específica atual da madeira de eucalipto: obtido pela amostragem ao longo de 10 toras, no sentido longitudinal e radial. Sendo a metodologia de análise baseada no método do máximo teor de umidade de Vital (1984), e o valor apresentado a média do total da amostragem. . 


\section{Dados estimados}

Volume $\left(\mathrm{m}^{3}\right)$ de resíduos: todos os resíduos são descartados, com exceção das peças aproveitáveis da serra circular 1, que são direcionadas para a serra circular 2. A estimativa do total de resíduos por máquina foi obtida pela subtração do total de saída do total de entrada, com exceção para a máquina de serra fita, onde foi em que foram aplicados os fatores de produção de serragem e costaneiras proposto por Garcia (1992).

Poder calorífico líquido da madeira de eucalipto: $1750 \mathrm{kcal} / \mathrm{kg}$ a $50 \%$ de umidade

Volume $\left(\mathrm{m}^{3}\right)$ de pranchões: estimado pela subtração do volume de entrada de toras, os fatores de porcentagem de produção em serraria de costaneiras (14\%) e serragem (4\%), segundo Garcia (citado por Borges, 1993).

Volume $\left(\mathrm{m}^{3}\right)$ de peças aproveitáveis (Vap): foi estimado utilizando os fatores de Garcia (1992) para serragem e costaneira, e a diferença do volume de entrada e o volume de peça processada:

Vap = Ven - Vpe $-($ Ven x 0,18);

Em que: Ven = volume de entrada; $\mathrm{Vpe}=$ volume de peças.

\section{Obtenção do balanço de massa}

O balanço de massa foi calculado por máquina através de medição direta do material de entrada e cálculo de estimativa do material de saída, e o somatório dos balanços individuais forneceu o balanço total.

\section{Obtenção do balanço de energia} balanço total.

O balanço energético foi calculado por máquina, e o somatórios dos balanços individuais forneceu o

A energia de entrada é a energia calorífica (kcal) das toras de madeira.

A quantidade de energia consumida (Qec) é a soma do consumo elétrico (kwh) convertido para kcal da máquina (Qee), mais energia corpórea em kcal (Qeh) e a energia perdida (kcal) na forma de resíduos (Qer).

Qec $=$ Qee + Qeh + Qer abaixo:

$\mathrm{O}$ cálculo da energia produzida pela massa de madeira em energia $(\mathrm{Q})$ foi feita segundo a equação

\section{$\mathrm{Q}=$ PCLu $\times$ DATu $\times \mathrm{V}$}

Em que: $\mathrm{Q}=$ quantidade de energia produzida pela madeira $(\mathrm{kcal}) ; \mathrm{PCLu}=$ poder calorífico líquido à umidade "u" (Kcal/ kg); DATu = densidade atual da madeira na densidade "u"; V = volume de madeira ou resíduos.

Sendo o balanço final a diferença do total menos a consumida.

\section{Fator de eficiência de massa e energia}

A eficiência máxima (\%) de um equipamento de serraria em termos de massa e energia processada traduz-se na produção mínima de resíduos (perdas). Dos resíduos gerados nesta serraria, as aparas e costaneiras são consideradas como passíveis de serem reduzidas a um nível zero de produção, já que a otimização da linha de corte e a comercialização destas para outros fins as tornam resíduos não-descartáveis e que, portanto, se mantêm no sistema como madeira processada.

Assim, o único resíduo obrigatório é a serragem que é função da lâmina de corte, sendo que a quantidade gerada varia exclusivamente pelo número de cortes executados, mas sempre será impossível sua redução a zero e não é comercializada por falta de mercado consumidor.

Dessa forma, o fator de eficiência máxima traduz-se na subtração do total de madeira que entra para processamento menos o fator médio de produção de serragem, que o presente trabalho considerou como sendo $4 \%$ do total processado. Assim a eficiência máxima em massa foi considerada como $96 \%$ do total de madeira processada, e, para energia produzida, utilizou-se essa massa transformada em volume $\left(\mathrm{m}^{3}\right)$, convertida em $\mathrm{kcal} / \mathrm{he}$.

Deve-se ressaltar que esse fator deve ser adequado a cada situação com suas respectivas especificações. 


\section{Eficiência de massa e de energia}

A eficiência em massa foi dada por:

$E m=[($ massa de entrada $\times 0,96)-$ massa de resíduo produzida $) /($ massa de entrada $\times 0,96)] \times 100$

A eficiência energética foi dada por:

$\mathrm{Ee}=[(\mathrm{Q}$ entrada $\times 0,96)-\mathrm{Qec}) /(\mathrm{Q}$ entrada $\times 0,96)] \times 100$

\section{Rendimento em massa e energia}

Rendimento em massa $(\mathrm{Rm})=($ massa processada/massa de entrada $) \times 100$

Rendimento em energia $(\mathrm{Re})=($ energia da massa processada/energia de entrada) $\times 100$

\section{Parâmetro de julgamento}

Ao analisarmos os resultados em termos de eficiência e rendimento, consideramos como ponto máximo (ótimo) o valor de 100\% para ambas as variáveis. E consideramos que valores entre 80-100, representam uma situação ótima. Valores entre 50-80, foram considerados razoáveis e valores abaixo de 50 foram consideradas não-aceitáveis, já que a produção de massa ou energia é inferior à gasta no processo, gerando balanço negativo. Ressalta-se que esses são parâmetros criados neste trabalho, por não terem encontrados trabalhos similares que pudessem ser usados como padrão de comparação.

\section{RESULTADOS E DISCUSSÃO}

As figuras 1 e 2 apresentam os fluxogramas de massa e energia respectivamente encontrados pela aplicação da metodologia descrita anteriormente.

\section{Fluxogramas}

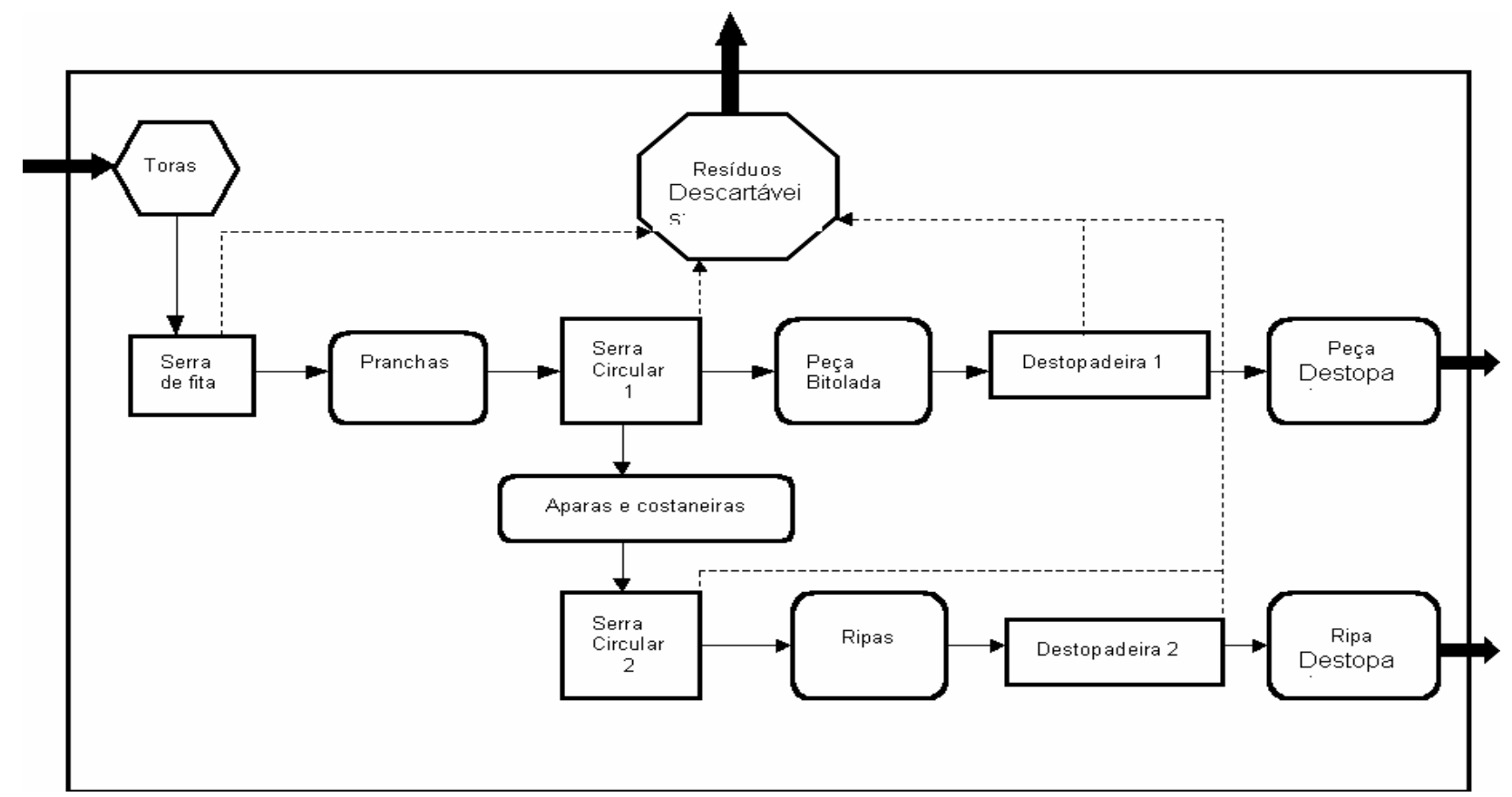

FIGURA 1: Fluxograma de massa.

FIGURE 1: Mass flow. 


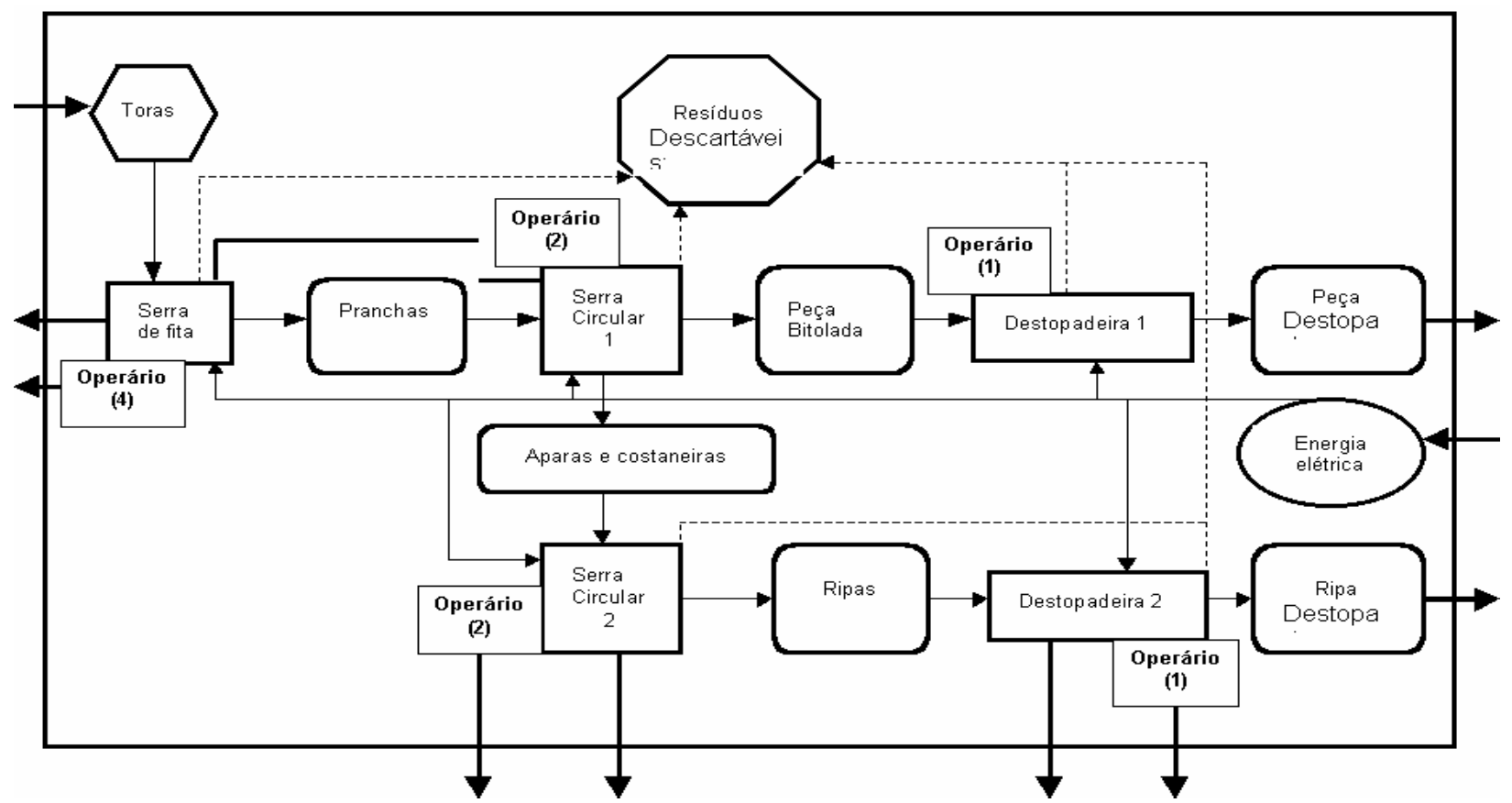

FIGURA 2: Fluxograma de energia.

FIGURE 2: Energy flow.

\section{Dados medidos e estimados} energia.

A Tabela 1 apresenta os valores calculados e estimados para cada ponto dos fluxogramas de massa e

TABELA 1: Dados calculados e estimados no levantamento.

TABLE 1: Calculate and estimate data of the survey.

\begin{tabular}{l|rrrrrr}
\hline Variáveis & \multicolumn{5}{|c}{ Maquinarios } \\
\cline { 2 - 6 } & Serra fita & Serra Circular 1 & Destopadeira 1 & Serra Circular 2 & Destopadeira 2 \\
\hline N. de operários & 4,00 & 2,00 & 1,00 & 2,00 & 1,00 \\
Massa específica $\left(\mathrm{g} / \mathrm{cm}^{3}\right)$ & 1,00 & 1,00 & 1,00 & 1,00 & 1,00 \\
Teor de umidade da madeira & 0,50 & 0,50 & 0,50 & 0,50 & 0,50 \\
Consumo de energia elétrica $(\mathrm{kwh} / \mathrm{he})$ & 10,55 & 3,58 & 1,01 & 4,89 & 1,30 \\
Volume de entrada $\left(\mathrm{m}^{3} / \mathrm{he}\right)$ & 2,30 & 2,86 & 1,37 & 1,79 & 0,48 \\
Volume de saída de material & 1,89 & 1,37 & 1,20 & 0,48 & 0,39 \\
processado $\left(\mathrm{m}^{3} / \mathrm{he}\right)$ & 0,41 & 1,49 & 0,17 & 1,44 & 0,10 \\
Volume de saída de resíduo $\left(\mathrm{m}^{3} / \mathrm{he}\right)$ & $2.300,90$ & $2.861,30$ & $1.372,80$ & $1.790,80$ & 485,30 \\
Massa de entrada $(\mathrm{kg} / \mathrm{he})$ & $1.886,70$ & $1.372,80$ & $1.199,10$ & 485,30 & 388,20 \\
Massa de saída de material & 414,20 & $1.489,00$ & 173,10 & $1.305,50$ & 97,00 \\
processado $(\mathrm{kg} / \mathrm{he})$ & 3,67 & 2,42 & 2,42 & 1,65 & 1,65 \\
Massa de saída de resíduo $(\mathrm{kg} / \mathrm{he})$ & $2.100,00$ & $1.050,00$ & 525,00 & $1.050,00$ & 525,00 \\
Horas efetivas de trabalho (diário) & $9.073,00$ & $3.078,80$ & 870,06 & $4.205,40$ & $1.118,00$ \\
Energia corpórea $(\mathrm{kcal} / \mathrm{he})$ & $3.301,72$ & $2.402,40$ & $2.098,42$ & $8.492,75$ & $6.793,50$ \\
Energia Elétrica $(\mathrm{kcal} / \mathrm{he})$ & & & & & \\
Energia da madeira processada & Mcal/he) & &
\end{tabular}

A Tabela 2 apresenta os valores em quilogramas por hora efetiva de massa encontrada por ponto da linha de produção e utilizados para o cálculo do balanço de massa por hora efetiva. 
TABELA 2: Balanço de massa por hora efetiva (he).

TABLE 2: Mass balance by efetive hour (he).

\begin{tabular}{l|c|c|c|c|c|c|c}
\hline Máquina & $\begin{array}{c}\text { Massa total de } \\
\text { entrada (kg)/ he } \\
(\mathrm{a})\end{array}$ & $\begin{array}{c}\text { Massa total de } \\
\text { peças }(\mathrm{kg}) / \mathrm{he} \\
(\mathrm{b})\end{array}$ & $\begin{array}{c}\text { Massa total } \\
\text { de resíduos } \\
(\mathrm{kg}) / \mathrm{he}\end{array}$ & $\begin{array}{c}\text { Quantidade } \\
\text { mínima de } \\
\text { resíduos } \\
(\mathrm{kg}) / \mathrm{he}\end{array}$ & $\begin{array}{c}\text { Quantidade máxima } \\
\text { de madeira } \\
\text { processada } \\
(\mathrm{kg}) / \mathrm{he}\end{array}$ & $\begin{array}{c}\mathrm{Rm} \\
(\%)\end{array}$ & $\begin{array}{c}\text { Em } \\
(\%)\end{array}$ \\
\hline Serra fita & 2300,90 & 1886,70 & 0414,10 & 092,04 & 2208,86 & 82,00 & 81,25 \\
Serra circular 1 & 2861,30 & 1372,80 & 1489,00 & 114,45 & 2746,85 & 47,98 & 45,79 \\
Destopadeira 1 & 1372,80 & 1199,10 & 0173,10 & 054,91 & 1317,89 & 87,35 & 86,87 \\
Serra circular 2 & 1790,80 & 0485,30 & 1305,50 & 071,63 & 1719,17 & 27,10 & 24,06 \\
Destopadeira 2 & 0485,30 & 0388,20 & 0097,00 & 019,41 & 0465,89 & 79,99 & 79,18 \\
\hline
\end{tabular}

Em que: $\mathrm{Rm}=$ rendimento em massa $(\mathrm{Rm}=\mathrm{b} / \mathrm{a} \mathrm{x} 100) ; \mathrm{Em}=$ Eficiência em massa.

A Tabela 3 apresenta os valores em quilogramas por turno de massa encontrada por ponto da linha de produção e utilizados para o cálculo do balanço de massa por turno.

TABELA 3: Balanço de massa por turno $(t)$.

TABLE 3: Mass balance by period ( $\mathrm{t}$ ).

\begin{tabular}{l|c|c|c|c|c|c|c}
\hline Máquina & $\begin{array}{c}\text { Massa total de } \\
\text { entrada } \\
(\mathrm{kg})\end{array}$ & $\begin{array}{c}\text { Massa total de } \\
\text { peças } \\
(\mathrm{kg})\end{array}$ & $\begin{array}{c}\text { Massa total } \\
\text { de resíduos } \\
(\mathrm{kg})\end{array}$ & $\begin{array}{c}\text { Quantidade } \\
\text { mínima de } \\
\text { resíduos } \\
(\mathrm{kg})\end{array}$ & $\begin{array}{c}\text { Quantidade máxima } \\
\text { de madeira } \\
\text { processada } \\
(\mathrm{kg})\end{array}$ & $\begin{array}{c}\mathrm{Rm} \\
(\%)\end{array}$ & $\begin{array}{c}\text { Em } \\
(\%)\end{array}$ \\
\hline Serra fita & 8444,20 & 6924,20 & 1520,00 & 337,77 & 8106,43 & 82,00 & 81,25 \\
Serra circular 1 & 6924,20 & 3320,90 & 3603,30 & 276,968 & 6647,23 & 47,96 & 45,79 \\
Destopadeira 1 & 3320,90 & 2901,80 & 419,10 & 132,84 & 3188,06 & 87,38 & 86,85 \\
Serra circular 2 & 2954,90 & 800,70 & 2154,20 & 118,20 & 2836,70 & 27,10 & 24,06 \\
Destopadeira 2 & 800,70 & 640,60 & 160,10 & 32,03 & 768,67 & 80,00 & 79,17 \\
\hline
\end{tabular}

Em que: $\mathrm{Rm}=$ rendimento em massa; $\mathrm{Em}$ = eficiência em massa.

Observando os equipamentos isoladamente por hora efetiva, concluiu-se que em termos de massa, a serra fita e as destopadeiras 1 e 2 possuem eficiência e rendimento satisfatórios com uma porcentagem de perda não muito alta.

A serra circular 1, possui eficiência e rendimento não-satisfatório, gerando um volume de perda superior ao volume de peças produzidas. Para melhoria de sua rentabilidade, e redução dos resíduos gerados, deve-se averiguar o gabarito de corte a ser utilizado, buscando um melhor aproveitamento da tora. Este maior aproveitamento deve ser em função não somente de um melhor delineamento do gabarito, mas também na diversificação de peças a serem produzidas, aumentando a taxa de aproveitamento do material de entrada.

A serra circular 2 foi o equipamento com mais baixo rendimento e eficiência. Entre as causas, considera-se as mesmas da serra circular 1 que são um gabarito de corte inadequado e a falta de um melhor planejamento objetivando uma maior diversidade de peças a serem produzidas, melhorando o rendimento e reduzindo a produção de resíduos. Mas se deve ressaltar que os valores foram afetados significativamente pelo "lay-out" de disposição das máquinas ao longo da linha de produção. Esse "lay-out" impõe, como material de entrada para a serra circular 2, o material de saída da 1. E esse material, por ser trabalhado de forma inadequada na 1, entra no sistema da 2 com baixa flexibilidade de trabalho, por causa de um padrão inexistente das peças de entrada, dificultando a otimização do planejamento do gabarito de corte e um melhor aproveitamento desse material por uma maior diversificação das peças produzidas na serra 2 .

A análise pela média diária dos equipamentos isoladamente demonstrou um comportamento similar à da análise por hora efetiva, não cabendo qualquer conclusão adicional à aquelas já citadas.

A Tabela 4 apresenta os valores em quilogramas por hora efetiva de massa encontrada por linha e utilizados para o cálculo do balanço de massa por linha e hora efetiva. 
TABELA 4: Balanço de massa por hora efetiva (he).

TABLE 4: Mass balance by efetive hour (he).

\begin{tabular}{c|c|c|c|c|c|c|c}
\hline Linha & $\begin{array}{c}\text { Massa total } \\
\text { de entrada } \\
(\mathrm{kg}) / \mathrm{he}\end{array}$ & $\begin{array}{c}\text { Massa total } \\
\text { de peças } \\
(\mathrm{kg}) / \mathrm{he}\end{array}$ & $\begin{array}{c}\text { Massa total } \\
\text { de resíduos } \\
(\mathrm{kg}) / \mathrm{he}\end{array}$ & $\begin{array}{c}\text { Quantidade mínima de } \\
\text { resíduos } \\
(\mathrm{kg}) / \mathrm{he}\end{array}$ & $\begin{array}{c}\text { Quantidade máxima de } \\
\text { madeira processada } \\
(\mathrm{kg}) / \mathrm{he}\end{array}$ & $\begin{array}{c}\mathrm{Rm} \\
(\%)\end{array}$ & $\begin{array}{c}\text { Em } \\
(\%)\end{array}$ \\
\hline 1 & $2.300,90$ & $1.199,10$ & $2.076,30$ & 92,04 & $2.208,86$ & 52,11 & 6,00 \\
2 & $1.790,80$ & 388,20 & $1.402,60$ & 71,63 & $1.719,17$ & 21,68 & 18,41 \\
\hline Total & $2.300,90$ & $1.587,30$ & $2.137,47$ & 92,04 & $2.208,86$ & 68,99 & 03,23 \\
\hline
\end{tabular}

Em que: $\mathrm{Rm}=$ rendimento em massa; $\mathrm{Em}=$ eficiência em massa.

A Tabela 5 apresenta os valores em quilogramas por turno de massa encontrada por linha e utilizados para o cálculo do balanço de massa por turno.

TABELA 5: Balanço de massa por turno ( $\mathrm{t})$.

TABLE 5: Mass balance by period ( $\mathrm{t})$.

\begin{tabular}{c|c|c|c|c|c|c|c}
\hline Máquina & $\begin{array}{c}\text { Massa total de } \\
\text { entrada } \\
(\mathrm{kg})\end{array}$ & $\begin{array}{c}\text { Massa total } \\
\text { de peças } \\
(\mathrm{kg})\end{array}$ & $\begin{array}{c}\text { Massa total } \\
\text { de resíduos } \\
(\mathrm{kg})\end{array}$ & $\begin{array}{c}\text { Quantidade mínima de } \\
\text { resíduos } \\
(\mathrm{kg})\end{array}$ & $\begin{array}{c}\text { Quantidade máxima de } \\
\text { madeira processada } \\
(\mathrm{kg})\end{array}$ & $\begin{array}{c}\mathrm{Rm} \\
(\%)\end{array}$ & $\begin{array}{c}\text { Em } \\
(\%)\end{array}$ \\
\hline Linha 1 & 8444,20 & 2901,80 & 5542,40 & 337,77 & 8106,43 & 34,36 & 31,63 \\
Linha 2 & 2954,90 & 640,60 & 2314,30 & 118,20 & 2836,70 & 21,67 & 18,41 \\
\hline Total & 8444,20 & 3542,40 & 4901,79 & 337,77 & 8106,43 & 41,95 & 39,53 \\
\hline
\end{tabular}

Em que: $\mathrm{Rm}=$ rendimento em massa; Em = eficiência em massa.

A análise, por hora efetiva do conjunto de equipamentos da linha 1, mostrou que essa tem um rendimento satisfatório, mas necessita de melhoria em seu planejamento, pois sua eficiência é muito baixa, não sendo satisfatória. Dois fatores são marcantes neste sentido: o primeiro, já citado na análise individual, é a falta de um planejamento adequado do corte na serra circular 1, e o segundo é a falta de equilíbrio entre a produção por hora efetiva dos equipamentos quando analisados em conjunto. A serra circular, não se encontra em equilíbrio com a serra fita. Dessa forma, ocorre, na serra fita, uma maior produção de peças e resíduos do que o restante do sistema pode absorver. Essa diferença se traduz em baixo rendimento da linha como um todo, e uma produção de resíduos superior ao ideal por hora efetiva de trabalho. Ocorrendo a mesma situação entre a serra circular 1 e a destopadeira 1.

Ao analisar a linha 2 por hora efetiva, percebe-se que essa apesar de ter um rendimento e eficiência não-satisfatório, tem como principal causa de sua inadequação produtiva o reflexo da má utilização do material processado na linha 1 que é a fonte de entrada da linha 2. Portanto, a melhoria da linha 1 , ou a abertura dessa, para trabalhar associada diretamente com a serra fita, trará reflexo positivo sobre a linha 2.

O sistema total de produção possui uma eficiência produtiva satisfatória, necessitando de reformulação do seu "lay-out", pois ele se encontra com desequilíbrio entre a capacidade de produção por hora efetiva de trabalho da serra fita e a capacidade de absorção dos maquinários seguintes existentes na linha, já observado de forma isolada na Linha 1 . E que ocorre também entre a linha 1 e 2 , quando se observa todo o conjunto. Essa falta de equilíbrio ocasiona uma maior geração de resíduos em relação à quantidade de peças produzidas, baixando o rendimento por hora efetiva. E o seu rendimento torna-se não-aceitável. A diferença entre o rendimento e a eficiência, é conseqüente do rendimento não contabilizar todos as perdas em termos de energia e massa, observando somente a diferença entre a entrada e a saída. E a eficiência contabiliza todas as entrada e saídas ao longo do sistema.

Ao analisar o sistema como um todo por turno, e por esta não diferenciar tempo parado de tempo corrido de cada equipamento dentro da linha ou sistema, pode-se observar diferença nas duas análises. As principais diferenças estão em um valor de rendimento e eficiência inferior ao por hora efetiva na linha 1, demonstrando que mesmo sem considerar a falta de equilíbrio entre a produção e capacidade de absorção entre os equipamentos, faz-se realmente necessária a reformulação do planejamento do gabarito de corte, e da otimização na utilização das toras, por meio de uma maior diversidade de peças a serem produzidas.

A linha 2 manteve seus índices de rendimento e eficiência, reforçando a conclusão de que seu baixo rendimento e eficiência têm forte influência do reflexo direto da inadequação da linha 1 , sobretudo da serra circular 1 que provê o material de entrada da linha 2, assim como em conseqüência da subutilização de um 
equipamento com maior potencial produtivo, do que para o qual ele foi direcionado.

Mas ao desconsiderar a sincronia de produção entre os equipamentos, ocorreu redução da rentabilidade e aumento da eficiência no conjunto das duas linhas. Esse fato serve para demonstrar a importância da análise por hora efetiva, por ser mais completa e permitir conclusões mais adequadas para o ajuste do sistema. Pois esse aumento não é função de uma melhoria real, mas, sim, por desconsiderar um fator negativo que é a falta de equilíbrio do fluxo de massa entre os equipamentos que compõe a linha.

\section{Balanço de energia e análise}

A Tabela 6 apresenta os valores em Mcal por hora efetiva de energia encontrada por ponto da linha de produção e utilizados para o cálculo do balanço de energia por hora efetiva.

TABELA 6: Balanço de energia por hora efetiva (he).

TABLE 6: Energy balance by efective hour (he).

\begin{tabular}{l|c|c|c|c|r|r|r|r|r}
\hline Máquina & $\begin{array}{c}\text { Qen } \\
(\mathrm{Mcal} / \mathrm{he})\end{array}$ & $\begin{array}{c}\text { Qep } \\
(\mathrm{Mcal} / \mathrm{he})\end{array}$ & $\begin{array}{c}\text { Qee } \\
(\mathrm{Mcal} / \mathrm{he})\end{array}$ & $\begin{array}{c}\text { Qeh } \\
(\mathrm{Mcal} / \mathrm{he})\end{array}$ & $\begin{array}{c}\text { Qer } \\
(\mathrm{Mcal} / \mathrm{he})\end{array}$ & $\begin{array}{c}\text { Qec } \\
(\mathrm{Mcal} / \mathrm{he})\end{array}$ & $\begin{array}{c}\text { Qmáx proc. } \\
(\mathrm{Mcal} / \mathrm{he})\end{array}$ & $\begin{array}{c}\text { Re } \\
(\%)\end{array}$ & $\begin{array}{c}\text { Ee } \\
(\%)\end{array}$ \\
\hline Serra fita & $4.026,57$ & $3.301,72$ & 9,07 & 2,10 & 724,67 & 735,84 & $3.865,50$ & 82,00 & 80,96 \\
Serra circular 1 & $5.007,27$ & $2.402,40$ & 3,09 & 1,05 & $2.604,87$ & $2.609,01$ & $4.806,99$ & 47,98 & 45,72 \\
Destopadeira 1 & $2.402,40$ & $2.098,42$ & 0,87 & 0,52 & 303,97 & 305,36 & $2.306,30$ & 87,34 & 86,75 \\
Serra circular 2 & $3.133,90$ & 849,27 & 4,20 & 1,05 & $2.284,62$ & $2.289,87$ & $3.008,54$ & 27,10 & 23,88 \\
Destopadeira 2 & 849,27 & 679,35 & 1,19 & 0,52 & 169,92 & 171,63 & 815,30 & 79,99 & 78,94 \\
\hline
\end{tabular}

Em que: $\mathrm{Re}$ = rendimento em energia; Ee = eficiência energética; Qec = energia entrada; Qep = energia da madeira processada; Qee = energia elétrica consumida; Qeh = energia corpórea; Qeh = energia dos resíduos; Qec $=$ energia consumida; $\mathrm{Q}$ máx = quantidade máxima de energia no processo.

A Tabela 7 apresenta os valores em Mcal por turno de energia encontrada por ponto da linha de produção e utilizados para o cálculo do balanço de energia por turno.

TABELA 7: Balanço de energia por turno $(t)$.

TABLE 7: Energy balance by period $(\mathrm{t})$.

\begin{tabular}{l|rr|c|c|r|r|r|r|r}
\hline Máquina & \multicolumn{1}{c}{$\begin{array}{c}\text { Qen } \\
(\mathrm{Mcal} / \mathrm{d})\end{array}$} & \multicolumn{1}{c}{$\begin{array}{c}\text { Qep } \\
(\mathrm{Mcal} / \mathrm{d})\end{array}$} & $\begin{array}{c}\text { Qee } \\
(\mathrm{Mcal} / \mathrm{d})\end{array}$ & $\begin{array}{c}\text { Qeh } \\
(\mathrm{Mcal} / \mathrm{d})\end{array}$ & $\begin{array}{c}\text { Qer } \\
(\mathrm{Mcal} / \mathrm{d})\end{array}$ & $\begin{array}{c}\text { Qec } \\
(\mathrm{Mcal} / \mathrm{d})\end{array}$ & $\begin{array}{c}\text { Qmáx proc. } \\
(\mathrm{Mcal} / \mathrm{d})\end{array}$ & $\begin{array}{c}\text { Re } \\
(\%)\end{array}$ & $\begin{array}{c}\text { Ee } \\
(\%)\end{array}$ \\
\hline Serra fita & $14.777,35$ & $12.117,35$ & 33,28 & 7,70 & $2.660,00$ & $2.700,98$ & $14.186,25$ & 82,00 & 80,96 \\
Serra circular 1 & $12.117,35$ & $5.811,57$ & 7,45 & 2,54 & $6.305,77$ & $6.315,76$ & $11.632,65$ & 47,96 & 45,71 \\
Destopadeira 1 & $5.811,57$ & $5.078,15$ & 2,10 & 1,27 & 733,42 & 736,79 & $5.579,11$ & 87,38 & 86,79 \\
Serra circular 2 & $5.171,07$ & $1.401,22$ & 6,94 & 1,73 & $3.769,85$ & $3.778,52$ & $4.964,23$ & 27,10 & 23,88 \\
Destopadeira 2 & $1.401,22$ & $1.121,05$ & 1,84 & 0,87 & 280,17 & 282,88 & $1.345,18$ & 80,00 & 78,97 \\
\hline
\end{tabular}

Em que: $\mathrm{Re}=$ rendimento em energia; Ee $=$ eficiência energética; Qec $=$ energia entrada; Qep = energia da madeira processada; Qee = energia elétrica consumida; Qeh = energia corpórea; Qeh = energia dos resíduos; Qec $=$ energia consumida; $\mathrm{Q}$ máx = quantidade máxima de energia no processo.

A análise isolada dos equipamentos mostrou um comportamento similar ao do fluxo de massa pelo fluxo de energia. Nesse contexto, a serra fita e as destopadeiras 1 e 2 possuem eficiência e rendimento ótimas com baixa perda da energia empregada.

A serra circular 1 possui eficiência e rendimento não-satisfatório, gerando uma perda de energia superior ao mantido no sistema. A melhora de sua rentabilidade e redução do desperdício devem ser por meio de um melhor aproveitamento da energia introduzida no sistema. Assim como no fluxo de massa, o melhor aproveitamento deve ser em função não-somente de um melhor delineamento do gabarito de corte e diversificação de peças a serem produzidas, como também na busca de utilização dos resíduos gerados que podem ser usados para queima em fornos ou produção de briquetes, permitindo uma maior aproveitamento da energia que eles representam.

Outra similaridade em relação ao fluxo de massa é o comportamento da serra circular 2, sendo novamente o equipamento com mais baixo rendimento e eficiência. Entre as causas, citam-se as mesmas da serra circular 1, que são um gabarito de corte inadequado e a falta de um melhor planejamento buscando uma maior diversidade de peças a serem produzidas, melhorando o rendimento e desperdício de energia potencial. Mas deve-se ressaltar que, assim como no fluxo de massa, esses valores têm influência direta do processo inadequado na serra circular 1, pelos mesmos motivos já citados na análise anterior. 
A Tabela 8 apresenta os valores em Mcal por hora efetiva de energia encontrada por linha de produção e utilizados para o cálculo do balanço de energia por hora efetiva.

TABELA 8: Balanço de energia por hora efetiva (he) nas linhas 1 e 2, e sistema total.

TABLE 8: Energy balance by efetive hour (he), in the lines 1 and 2, and in the total system.

\begin{tabular}{ccc|cc|c|c|c|c|c|c}
\hline Linha & $\begin{array}{c}\text { Qen } \\
(\mathrm{Mcal} / \mathrm{h})\end{array}$ & $\begin{array}{c}\text { Qep } \\
(\mathrm{Mcal} / \mathrm{he})\end{array}$ & $\begin{array}{c}\text { Qee } \\
(\mathrm{Mcal} / \mathrm{he})\end{array}$ & $\begin{array}{c}\text { Qeh } \\
(\mathrm{Mcal} / \mathrm{he})\end{array}$ & $\begin{array}{c}\text { Qer } \\
(\mathrm{Mcal} / \mathrm{he})\end{array}$ & $\begin{array}{c}\text { Qec } \\
(\mathrm{Mcal} / \mathrm{he})\end{array}$ & $\begin{array}{c}\text { Qmáx proc. } \\
(\mathrm{Mcal} / \mathrm{he})\end{array}$ & $\begin{array}{c}\text { Re } \\
(\%)\end{array}$ & $\begin{array}{c}\text { Ee } \\
(\%)\end{array}$ \\
\hline 1 & $4.026,57$ & $2.098,42$ & 13,03 & 3,67 & $3.633,52$ & $3.650,22$ & $3.865,51$ & 52,11 & 5,57 \\
2 & $3.133,90$ & 679,35 & 5,39 & 1,57 & $2.454,55$ & $2.461,51$ & $3.008,54$ & 21,68 & 18,18 \\
\hline Total & $4.026,57$ & $2.777,77$ & 18,34 & 5,25 & $3.741,47$ & $3.765,06$ & $3.865,51$ & 68,99 & 2,60 \\
\hline
\end{tabular}

Em que: Re = rendimento em energia; Ee = eficiência energética; Qec = energia entrada; Qep = energia da madeira processada; Qee = energia elétrica consumida; Qeh = energia corpórea; Qeh = energia dos resíduos; Qec = energia consumida; $\mathrm{Q}$ máx = quantidade máxima de energia no processo.

A Tabela 9 apresenta os valores em Mcal, por turno, de energia encontrada por linha de produção e utilizados para o cálculo do balanço de energia por turno.

TABELA 9: Balanço de energia por turno $(t)$ nas linhas 1 e 2, e sistema total.

TABLE 9: Energy balance by period $(\mathrm{t})$, and in the total system.

\begin{tabular}{c|c|c|c|c|c|c|c|c|c}
\hline Linha & $\begin{array}{c}\text { Qen } \\
(\mathrm{Mcal} / \mathrm{t})\end{array}$ & $\begin{array}{c}\text { Qep } \\
(\mathrm{Mcal} / \mathrm{t})\end{array}$ & $\begin{array}{c}\text { Qee } \\
(\mathrm{Mcal} / \mathrm{t})\end{array}$ & $\begin{array}{c}\text { Qeh } \\
(\mathrm{Mcal} / \mathrm{t})\end{array}$ & $\begin{array}{c}\text { Qer } \\
(\mathrm{Mcal} / \mathrm{t})\end{array}$ & $\begin{array}{c}\text { Qec } \\
(\mathrm{Mcal} / \mathrm{t})\end{array}$ & $\begin{array}{c}\text { Qmáx proc. } \\
(\mathrm{Mcal} / \mathrm{t})\end{array}$ & $\begin{array}{c}\text { Re } \\
(\%)\end{array}$ & $\begin{array}{c}\text { Ee } \\
(\%)\end{array}$ \\
\hline 1 & 14777,35 & 5078,15 & 42,85 & 11,52 & 9699,20 & 9753,57 & 14186,26 & 34,36 & 31,25 \\
2 & 05171,07 & 1121,05 & 08,78 & 02,60 & 4050,02 & 4061,40 & 04964,23 & 21,68 & 18,19 \\
\hline Total & 14777,35 & 6199,20 & 51,64 & 14,12 & 8578,15 & 8643,91 & 14186,26 & 41,95 & 39,07 \\
\hline
\end{tabular}

Em que: $\mathrm{Re}=$ rendimento em energia; Ee $=$ eficiência energética; Qec $=$ energia entrada; Qep $=$ energia da madeira processada; Qee = energia elétrica consumida; Qeh = energia corpórea; Qeh = energia dos resíduos; Qec = energia consumida; $\mathrm{Q}$ máx = quantidade máxima de energia no processo.

A análise conjunta dos equipamentos da linha 1, em termos de energia, mostrou comportamento similar ao fluxo de massa. Assim como a linha 2 e o sistema total de produção. Reforçando a necessidade de total reformulação, tendo como principal causa a falta de equilíbrio ao longo do fluxo de massa e energia.

Tendo como diferenças entre a análise diária e a por hora efetiva, um valor de rendimento e eficiência inferior ao por hora efetiva na linha 1, demonstrando que, mesmo sem considerar o desequilíbrio entre a produção dos equipamentos, se faz realmente necessária a reformulação do planejamento do gabarito de corte, e da otimização na utilização das toras, por meio de uma maior diversidade de peças a serem produzidas.

A linha 2 manteve baixos índices de rendimento e eficiência, novamente reforçando a conclusão de que seu rendimento e eficiência têm forte influência do reflexo direto da inadequação da linha 1 , sobretudo da serra circular 1 que é a principal fonte de material da linha 2.

Mas ao desconsiderar o equilíbrio do fluxo de produção entre os equipamentos, ocorreu um aumento da rentabilidade, com redução da eficiência como um todo. Reforça-se a importância da análise por hora efetiva que permite conclusões mais aprofundadas. Pois, assim com no fluxo de massa, no fluxo de energia, esse aumento não é função de uma melhoria real, mas, sim, por desconsiderar um fator negativo que é a falta de equilíbrio de produção entre os equipamentos que compõem a linha. E que aqui, em função dos outros fatores envolvidos como a energia humana e elétrica, tem a média dos valores menores em relação aos valores da análise do fluxo de massa.

\section{CONCLUSÕES}

De posse das análises, conclui-se que o sistema atual se apresenta totalmente inadequado em relação ao seu balanço de massa e energia. Apesar de apresentar uma produção diária, com rendimento por maquinário e no conjunto razoáveis, a eficiência deve ser melhorada, pois é extremamente baixa quando se analisa o sistema por hora efetiva de trabalho e por turno, tanto em termos de massa como energia.

Para melhoria de eficiência que irá gerar um impacto positivo sobre a rentabilidade, as principais soluções se encontram em um melhor planejamento do gabarito de corte das toras, com a inclusão de uma maior diversidade de peças comerciais processadas, reduzindo o desperdício na serra circular 1 , que é um 
ponto de estrangulamento do sistema como um todo. Pois além de reduzir as médias em termos de massa e energia da linha 1, tem influência direta sobre a linha 2.

Para melhorar a eficiência, o layout do sistema deve ser alterado buscando um melhor equilíbrio da produção por hora efetiva entre os diferentes maquinários. Esse equilíbrio está relacionado primeiramente com a nova capacidade da serra circular 1, na qual o ponto ideal seria a redução na entrada de massa, e aumento da massa de produto gerado. Com essa alteração, a linha 2 seria desvinculada da linha 1 , sendo ligada diretamente à serra fita, aumentando a sua possibilidade de produção, através do auxílio na absorção da produção da serra fita. Ressalta-se também que em função da serra circular 1 e 2 serem iguais e utilizarem a mesma energia e número de operadores. Torna-se fácil concluir que, com essa mudança, o equilíbrio de fluxo irá melhorar significativamente, pelo aumento de produção diária.

Outra opção é o desligamento total da linha 2 e redução da produção da serra fita, igualando essa à capacidade de absorção da serra circular 1, melhorando o equilíbrio do fluxo e, conseqüentemente, sua rentabilidade e eficiência. Mas apesar da melhora entre de produção e perda, isso provavelmente reduzirá a receita líquida total, podendo tornar o sistema inviável economicamente.

Recomenda-se em ambas as opções a aquisição de maquinário específico para processamento dos resíduos, melhorando o potencial de comercialização desses. A escolha deve considerar a existência de mercado consumidor que viabilize o produto gerado.

\section{REVISÃO BIBLIOGRÁFICA}

BEHRENSMEYER, R.; BRINGESU, S.; SCHÜTZ H. Material flow accounts Part I - general aspects, Aluminium, National Overall Accounts. Luxemburgo : Wuppetal Institute, 1998. 94p.

BRASIL. Ministerio de Minas e Energia. Balanço energético nacional BEN 2002 : ano Base 2001. Brasília : Ministério de Minas e Energia, 2002. 141p.

BRITO, J. O. Expressão da produção florestal em unidades energéticas. In.: CONGRESSO NACIONAL FLORESTAL PANAMERICANO, 1.,1993 ; CONGRESSO FLORESTAL BRASILEIRO, 7., 1993. Anais... Curitiba : SBF : SBEF, 1993. p. 603-607.

BORGES, A.S.; CINIGLIO, G.; BRITO J.O. Considerações energéticas e econômicas sobre resíduos de madeira processada em serraria. In.: CONGRESSO NACIONAL FLORESTAL PANAMERICANO, 1. ,1993; CONGRESSO FLORESTAL BRASILEIRO, 7., 1993. Anais... Curitiba : SBF : SBEF, 1993. p. 280-282.

HÜTTLER, W.; KOWALSKI, M.F. Society's metabolism : the state of the art. The intellectual history of material flow analysis, Part II 1970-1998. Vienna : University of Vienna, 1998. 31p.

FERRÃO, P.C. Introdução à gestão ambiental : avaliação do ciclo de vida de produtos. Lisboa : IST Press, 1998. $217 \mathrm{p}$.

SERRA, G.E.; MOREIRA, J.R.; GOLDENBERG, J.; HEEZEN, A.M. Avaliação da energia investida na fase agrícola de algumas culturas. Brasília : Ministério da Indústria e Comércio. Secretaria de Tecnologia Industrial, 1979. 86p.

VITAL, B.R. Métodos de determinação da densidade da madeira. Boletim Técnico Sociedade de Investigações Florestais, Viçosa, n. 2, p. 1-21, 1984.

VITAL, B.R. Métodos para determinação do teor e umidade da madeira. Boletim Téenico Sociedade de Investigações Florestais, Viçosa, n. 13, p.1-33, 1997. 